\title{
INTRODUÇÃO. GÉNERO, PROFISSÕES E CARREIRAS: OPORTUNIDADES, CONSTRANGIMENTOS E DESAFIOS. UMA NOTA INTRODUTÓRIA
}

\author{
Gina Gaio Santos e Teresa Caroalho
}

Escola de Economia e Gestão, Universidade do Minho, Portugal

Departamento de Ciências Sociais, Políticas e do Território, Universidade de Aveiro, Portugal

As profissões e os grupos profissionais estão expostos nas sociedades contemporâneas a um conjunto de desafios diversos. Desde logo, destacam-se as alterações no papel do Estado na sociedade, que se afasta crescentemente de uma atitude protecionista, substituindo os seus modos tradicionais de regulação. Não menos importantes são os efeitos de uma globalização galopante, traduzida na existência de um mercado de trabalho cada vez mais internacional. As mudanças na organização social do trabalho potenciadas por uma complexificação da divisão do trabalho traduzem, por seu lado, o proliferar de novas profissões que resultam em emaranhadas linhas de subalternização e co-dependência entre os diferentes grupos. Simultaneamente, o desenvolvimento e crescente uso das novas tecnologias é, muitas vezes, assumido como resultando em processos de desqualificação e até proletarização dos profissionais (Freidson, 2001; Evetts, 2003; Kirkpatrick et al., 2005; Kuhlmann e Saks, 2008; Carvalho et al., 2013; Carvalho, 2012, 2014).

Para a emergência destes processos terá contribuído, também, a crescente massificação e feminização do ensino superior. As reformas introduzidas pelo processo de Bolonha, no contexto europeu, apesar do enfoque do ensino superior na promoção da empregabilidade dos/as graduados/as, têm resultado na desvalorização das credenciais académicas no mercado de trabalho; ao mesmo tempo que o discurso da empregabilidade continua a ignorar a persistência de desigualdades de género numa sociedade orientada para o conhecimento onde se enfatiza crescentemente a responsabilidade individual na autogestão da carreira e empregabilidade (Brown, Hesketh, e Williams, 2003; Moreau e Leathwood, 2006).

São amplamente conhecidas e estudadas as tendências para a segregação horizontal e vertical no mercado de trabalho, com efeitos diretos nas perceções dominantes sobre o lugar de homens e mulheres entre os e nos diversos grupos profissionais. Decorrente de uma multiplicidade de causas, de entre as quais cabe destacar as distintas representações dominantes sobre os papéis sociais atribuídos a homens e mulheres, é possível constatar uma tendência universal para a concentração das mulheres e dos homens em diferentes tipos de atividades profissionais e, dentro de cada grupo profissional, para uma concentração das mulheres nos níveis mais baixos da hierarquia profissional.

Esta associação decorre, como bem o demonstrou Anne Witz (2002), da estreita ligação entre profissionalismo e paternalismo. Numa sociedade patriarcal as mulheres estão sujeitas a processos de exclusão que invadem o domínio das 
profissões. Recorrendo ao uso do conceito de fechamento social, desenvolvido para explicitar o modo como os grupos profissionais procuram aumentar o seu poder e estatuto na sociedade (Parkin, 1979; Murphy, 1988), é possível procurar incorporar as dinâmicas de género associadas ao domínio das profissões. Uma análise abrangente dos processos profissionais implica, necessariamente, classificar os agentes/atores em termos de género. Esta rutura com uma perspetiva androcêntrica das profissões implica a consciencialização da capacidade de ação das mulheres. Isto é, embora as mulheres sejam sujeitas a estratégias de exclusão, traduzidas em maiores dificuldades em integrarem profissões tradicionalmente conotadas com a masculinidade e em ascender a posições de topo nos grupos em que se inserem, estas possuem a capacidade de desafiar as estratégias estabelecidas desenvolvendo elas próprias 'contra estratégias' que lhes permitem aspirar à inclusão nas estruturas e posições de que se sentem excluídas.

Neste número especial são apresentados alguns estudos que exemplificam estas dinâmicas. Tal é o caso do artigo 'Questões de género em arquitetura. História(s), espaço(s) e experiências profissionais e arquitetónicas' de Lia Antunes. Neste texto, a autora apresenta uma reflexão sóciohistórica sobre as dinâmicas que têm vindo a permitir uma consistente associação entre a arquitetura e a masculinidade, do mesmo modo que identifica momentos e atores capazes de romper com o domínio desta associação, permitindo afirmar o lugar e o papel das mulheres como sendo igualmente relevante neste domínio.

Ana Filipa Carvalho e Emília Fernandes, no artigo 'Processos de discriminação de profissionais imigrantes e qualificadas em contextos laborais tipicamente masculinos', refletem sobre os desafios que a dupla condição de mulheres e de migrantes apresenta às investigadoras que procuram integrar-se na carreira docente do ensino superior em Portugal. As autoras demonstram, com base no material empírico recolhido, que estas mulheres são alvo de dupla discriminação. A profissão académica, sendo tradicionalmente considerada de elite (Perkin, 1987) e sustentada no quadro de uma cultura organizacional que, apesar de assumida como neutra, se define como marcadamente masculina (Hearn, 2001; Carvalho e Machado-Taylor, 2010), foi sendo capaz de manter o seu estatuto e poder nas sociedades patriarcais através da definição e implementação de processos ou estratégias de exclusão assumidas tanto nas barreiras à entrada quanto nos mecanismos de promoção e evolução na carreira. Não obstante, os artigos de Jenny Neale e Kate White 'The university environment: opportunities, constraints and challenges for senior women', bem como de Kate White e Maria de Lourdes Machado-Taylor 'Gender and non-typical academic careers' demonstram, numa dimensão de reflexibilidade sobre a prática, o modo como as mulheres, em diferentes contextos e distintas situações, são elas próprias capazes de definir estratégias de forma mais ou menos consciente, e com maior ou menor apoio, que lhes permitam a integração e afirmação numa cultura organizacional adversa ao que se apresenta como diferenciador de uma normalidade socialmente assumida. No primeiro caso, as autoras refletem sobre o modo como uma cultura organizacio- 
nal marcadamente masculina pode ter impactos mais relevantes nas mulheres com carreiras atípicas. No segundo, são apresentados dois exemplos de histórias de vida, que testemunham a importância da relação entre a existência de mentores e a resiliência no contexto da academia. Neste domínio, é particularmente relevante o papel desempenhado pelos homens no apoio às estratégias desenvolvidas pelas mulheres.

Concomitantemente, o artigo de Álvaro Ribeiro 'Entre mulheres: o ensino doméstico e a profissão' produz uma reflexão sobre as orientações de carreira efetuadas por mulheres-mães que optam por um modelo de 'carreira' cuja configuração assume um caráter personalizado e ajustado às suas vivências pessoais e opções familiares. As mulheres-mães que optam pelo ensino doméstico dos/as filhos/as personificam, deste modo, o arquétipo da 'carreira sem fonteiras' (Arthur, 1994), que não se encontra delimitada por quaisquer fronteiras organizacionais, mas que se caracteriza pela autogestão numa afirmação de individualidade face à normatividade da carreira tradicional, que se deseja linear e ininterrupta, tal como concebe o modelo masculino de carreira (Schein, 1971). De notar que as carreiras profissionais das mulheres sempre conheceram especificidades e assumiram um desenvolvimento fragmentado e não-linear, sendo frequentemente descritas na literatura como mais diversas do que as carreiras masculinas (Guest e Sturges, 2007; Roberts, 2008).

À natureza fragmentada das carreiras das mulheres estão frequentemente associados processos de violência organizacional (Hearn e Parkin, 2001; Santos, 2011-2012). O conceito de violência é aqui entendido em lato sensu como compreendendo todas as estruturas organizacionais e ações individuais ou situações particulares que são sentidas como experiências que malfazem a identidade individual, entendida esta como multipolar e não como subsumida numa única dimensão. Assim, a violência organizacional refere-se não apenas a experiências de violência física ou moral, como sucede com o assédio sexual ou moral, mas também a outras formas mais subtis e invisíveis de violência e que incluem, entre outras, a vigilância constante do corpo e do 'ser feminino' ou 'ser masculino', as tentativas de subjugação e humilhação do/a) Outro/a que é diferente da norma, ou, ainda, as experiências de discriminação e exclusão organizacionais (Hearn e Parkin, 2001; Santos, 2011-2012). No artigo de Vera Fernandes, Delfina Gomes e João Leite Ribeiro 'A contabilidade, o acesso e o exercício da profissão de contabilista certificado na perspetiva das mulheres', bem como no de Maria João Silveirinha e Rita Basílio de Simões 'As mulheres tentam compensar. O verbo «compensar» é terrível, não é? Género e jornalismo em tempos de mudança', as mulheres contabilistas e jornalistas entrevistadas refletem precisamente sobre as suas vivências de violência organizacional. Tratam-se de experiências de discriminação ou exclusão associadas, por exemplo, aos discursos dominantes de que a maternidade implica um menor empenhamento profissional das mulheres e de uma cultura organizacional que privilegia o 'presenteismo' e as longas horas de trabalho como sinónimos de produtividade e bom desempenho organizacionais. 
Apesar de todas as transformações das últimas décadas, a gestão da esfera familiar e pessoal continua a ser vista no mundo organizacional e do trabalho como uma responsabilidade essencialmente da mulher (Santos, 2015), mesmo em carreiras profissionais muito exigentes, o que acaba por resultar no célebre 'efeito teto de vidro' e no bloqueio (invisível) da carreira daquelas. Daqui resulta que estas formas de violência organizacional ferem a competência destas mulheres no exercício da sua atividade profissional, seja enquanto contabilistas ou como jornalistas, não deixando de minar as suas possibilidades de progressão ou de sucesso profissional.

Com a organização deste dossier temático sobre 'Género, Profissões e Carreiras' quisemos refletir sobre os desafios, as oportunidades e os constrangimentos que se continuam a colocar às mulheres no mundo do trabalho e das profissões. Os artigos que aqui vos deixamos são um reflexo disso mesmo, mas não esgotam esta problemática que esperamos ver explorada à luz de novas interrogações e perspetivas de investigação.

\section{Referências bibliográficas}

Arthur, Michael (1994), «The boundaryless Career: A New Perspective for Organizational Inquiry», Journal of Organizational Behavior 15, 295-306.

Brown, Phillip; Hesketh, Anthony; Williams, Sara (2003), «Employability in a Knowledgedriven Economy», Journal of Education and Work 16, 107-126.

Carvalho, Teresa; Machado-Taylor, Maria de Lourdes (2010), «Gender and Shifts in Higher Education Managerial Regimes», Australian Universities Review 52(2), 33-42.

Carvalho, Teresa (2012), «Managerialism and Professional Strategies: A Case from Nurses in Portugal», Journal of Health, Organization and Management 26(4), 524-541.

Carvalho, Teresa; Ozkanli, Ozlem; Peterson, Helen; Prozesky, Helen (2013), «Building academic careers», in Barbara Bagilhole \& Kate White (eds), Battle Scars: Reflections of Women in Academia, Hampshire, Palgrave MacMillan, 127-168.

Carvalho, Teresa (2014), «Changing Connections between Professionalism and Managerialism: A Case Study of Nursing in Portugal», Journal of Professions and Organization 1(2) 1-15.

Evetts, Julia (2003), «The Sociological Analysis of Professionalism Occupational Change in the Modern World», International Sociology 18(2), 395-415.

Freidson, Eliot (2001), Professionalism The Third Logic, Cambridge, Polity Press.

Guest, David; Sturges, Jane (2007), «Living to work - working to live: conceptualizations of careers among contemporary workers», in Hugh Gunz e Maury Peiperl (eds.), Handbook of Career Studies, London, Sage, 310-326.

Hearn, Jeff (2001), «Academia, management and men: making the connections, exploring the implications», in Gender and the Restructured University: Changing Management and Culture in Higher Education. SRHE/Open University Press, Buckingham, UK, 69-89.

Hearn, Jeff; Parkin, Wendy (2001), Gender, Sexuality and Violence in Organizations: The Unspoken Forces of Organization Violations, London, Sage.

Kirkpatrick, Ian; Ackroyd, Stephen; Walker, Richard (2005), The New Managerialism and Public Service Professions, New York, Palgrave Macmillan. 
Kuhlmann, Ellen; Saks, Mike (eds.) (2008), Rethinking Professional Governance: International Directions in Health Care, London, The Polity Press.

Moreau, Marie-Pierre; Leathwood, Carole (2006), «Graduates' Employment and the Discourse of Employability: A Critical Analysis», Journal of Education and Work 19, 305-324 .

Murphy, Raymond (1988), Social Closure: The Theory of Monopolization and Exclusion, Oxford, Oxford University Press.

Parkin, Frank (1979), Marxism and Class Theory: A Bourgeois Critique, London, Tavistock.

Perkin, Harold (1987), "The academic profession in the United Kingdom», in Clark, Burton (ed.), The Academic Profession, London, The University of California Press, 13-59.

Roberts, Emma (2008), «Time and Work-life Balance: The Roles of Temporal Customization and Life Temporality», Gender, Work, and Organization 15, 430-453.

Santos, Gina Gaio (2015), «Narratives about Work and Family Life among Portuguese Academics», Gender, Work and Organization 22, 1-15.

Santos, Gina Gaio (2011-2012), «'Chaque Professeur a son Chien et son Assistant': Micropatriarchal Organization Violations in Academia», Journal of Workplace Rights 16(1), 83-106.

Schein, Edgar (1971), «The individual, the Organization and the Career: A Conceptual Scheme», The Journal of Applied Behavioral Science 7, 401-26.

Witz, Anne (2002), «Patriarchy and the professions. The gendered politics of occupational closure», in Stevi Jackson e Sue Scott (eds.), Gender: A sociological Reader, London, Psychology Press, 122-133.

\section{Gina Gaio Santos.}

Escola de Economia e Gestão, Universidade do Minho. gaiogina@eeg.uminho.pt

\section{Teresa Carvalho.}

Departamento de Ciências Sociais, Políticas e do Território, Universidade de Aveiro. teresa.carvalho@ua.pt 